\title{
BMJ Open Factors affecting consultant attitudes to undertaking undergraduate medical student teaching in the UK: a systematic review
}

\author{
Isobel Marion Harris (D , ${ }^{1}$ Heather McNeilly, ${ }^{2}$ Hani Benamer, ${ }^{2}$ Derek J Ward (D) , ${ }^{1}$ \\ Alice J Sitch, ${ }^{1,3}$ Jayne Parry ${ }^{1}$
}

To cite: Harris IM, McNeilly $\mathrm{H}$, Benamer $\mathrm{H}$, et al. Factors affecting consultant attitudes to undertaking undergraduate medical student teaching in the UK: a systematic review. BMJ Open 2021;11:e042653. doi:10.1136/ bmjopen-2020-042653

- Prepublication history and supplemental material is published online only. To view please visit the journal online (http://dx.doi.org/10.1136/ bmjopen-2020-042305).

Received 10 July 2020 Revised 24 November 2020 Accepted 22 December 2020

D) Check for updates

(c) Author(s) (or their employer(s)) 2021. Re-use permitted under CC BY-NC. No commercial re-use. See rights and permissions. Published by BMJ.

${ }^{1}$ Institute of Applied Health Research, University of Birmingham, Birmingham, UK ${ }^{2}$ Institute of Clinical Sciences, University of Birmingham, Birmingham, UK

${ }^{3}$ NIHR Birmingham Biomedical Research Centre, University Hospitals Birmingham NHS Foundation Trust and University of Birmingham, Birmingham, UK

Correspondence to

Isobel Marion Harris

i.m.harris@bham.ac.uk

\section{ABSTRACT}

Objective This systematic review aimed to explore consultant attitudes towards teaching undergraduate medical students in the UK.

Design Systematic review.

Methodology Standard systematic review methodology was followed. MEDLINE, EMBASE and OpenGrey were searched from inception to August 2019 to identify studies exploring senior doctors' attitudes towards teaching undergraduate medical students. Two reviewers independently carried out key methodological steps including study screening/selection, quality assessment and data extraction. A narrative synthesis was undertaken. Results Five studies were included in the review dating 2003-2015. Two studies used questionnaires, and three used focus groups/semistructured interviews. Key findings identified across all studies were consultants generally found teaching undergraduate medical students enjoyable, and consultants identified time constraints as a barrier to teaching. Other findings were consultants feeling there was a lack of recognition for time spent teaching, and a lack of training/guidance regarding teaching students. Conclusions This is the first systematic review to explore senior hospital doctors' attitudes towards teaching undergraduate medical students. Despite these five studies spanning 12 years, the same attitudes and issues regarding teaching are identified by all, suggesting lack of time particularly is a persistent problem regarding consultant-based teaching. An anecdotal impression is that consultants are no longer as enthusiastic about teaching as they once were, but it is evident over the 12 years of these studies that enjoyment levels, and presumably enthusiasm, have not changed significantly.

\section{INTRODUCTION}

\section{Rationale}

In the UK, medical schools offer undergraduate courses in medicine that usually last 5 or 6years depending on the institution and lead to registration as a doctor. These all follow a broadly similar structure; typically a focus on university-based learning is followed by clinical training, predominantly in hospitals. The majority of the clinical training
Strengths and limitations of this study

- This systematic review is the first to explore UK senior hospital doctors' attitudes towards teaching undergraduate medical students.

- Synthesis of data previously restricted to individual geographical regions has been carried out.

- Identification of mainly older studies (10+years) has highlighted the need for research on more recent developments in medical education.

- A limitation is the UK focus meaning the findings cannot be applied to non-UK settings.

has traditionally been the responsibility of senior hospital doctors (termed consultants in the English NHS) who have to balance teaching and clinical commitments. The past 20 years have seen a significant increase in medical student numbers in England, and subsequently this has required consultants to take on more undergraduate teaching duties. ${ }^{12}$ Additionally, the curriculum that is being taught and the methods of delivering the curriculum have undergone major changes, meaning medical education today is very different to what current senior consultants experienced. ${ }^{34}$ The focus on problembased learning and clinician-led small group tutorials has also increased the demand on consultants to deliver teaching. ${ }^{2}{ }^{4}$ Concerns about NHS understaffing and increasing future demand on hospital services, have resulted in plans to further increase medical student numbers, thereby placing even more demand on consultants for teaching. In 2018, the Royal College of Physicians published a briefing paper suggesting that an additional 7500 medical students per year were required to meet the projected demands on the health service by $2030 .{ }^{6}$ Before this, in 2017, the Department of Health announced that a further 1500 medical student places would 
be available from September $2018,{ }^{7}$ adding to the 1800 additional medical students that started training in $2017 .^{8}$

Existing literature about hospital-based undergraduate medical education and clinician-led teaching tends to have a specialty or subject-specific focus. ${ }^{9-14}$ This body of literature typically focuses on the provision of teaching, or the views of clinicians on what should be taught in a particular specialty rather than exploring the factors that lie behind senior clinicians' enthusiasm and involvement in undergraduate teaching itself. In a general practice setting, literature exists that more broadly explores the motivation for teaching, and the facilitators and barriers to general practitioners' involvement in undergraduate medical education. ${ }^{15-19}$ However, due to the differences in setting (hospital vs general practice) and employment pattern (the manner in which time is allocated to teaching varies greatly between senior clinicians working in hospitals and in general practice), findings in this literature are not directly transferable to a hospital setting.

In terms of hospital-based teaching, anecdotal evidence suggests that consultants in the UK are not enthusiastic about teaching, ${ }^{4}$ however there is published evidence to refute this. Hendry et $a l^{2}$ conducted a study in 2002 surveying consultants teaching undergraduate medical students from the University of Birmingham. They found that while teaching was seen as an enjoyable activity by many consultants, only a minority of consultants felt that there was adequate time and resources for teaching, and most felt they did not receive enough guidance, suggesting that individual enthusiasm is not a problem, but other factors are. These findings were mirrored in a study by $\mathrm{Stark}^{20}$ from 2003 interviewing consultants teaching in the Leeds Teaching Hospitals NHS Trust. Consultants again reported finding teaching undergraduates enjoyable, but feeling under considerable pressure from other professional commitments.

As an additional change to hospital-based teaching, a new role, the clinical teaching fellow (CTF) role, has been created within the NHS and grown in numbers rapidly. CTFs are doctors who have usually, as a minimum, completed 2years of foundation training and are employed to teach undergraduate medical students in UK hospitals, ${ }^{21}$ taking on teaching duties that were previously the responsibility of senior doctors. In 2005, there were 77 CTFs employed across the UK, ${ }^{22}$ but as of 2018 , there were 101 CTF posts in the North East of England alone, ${ }^{23}$ demonstrating the increase in the number of these posts. The CTF role is thought to be useful for delivering teaching to medical students, but as adjunct to consultant-based teaching due to their more junior level of clinical knowledge. ${ }^{21}$ Despite the rise in numbers of CTF posts, there is only very limited literature available about CTFs, and none available looking at any impact the role has had on consultant-based teaching, or vice versa.

While there are a few studies available exploring consultants' attitudes towards teaching, these are limited geographically to regions or individual hospitals, and no comprehensive evidence synthesis has been carried out to gain an understanding of factors affecting consultants' engagement with teaching across the UK. As medical student numbers continue to grow, and with changes to medical education such as curricula-based changes and the growth of new teaching roles in the form of the CTF role, it will be beneficial to have an understanding of factors impacting on consultants' attitudes towards teaching, so any strategies to facilitate teaching may be implemented country-wide.

\section{Objectives}

We aimed to undertake a systematic review to explore consultant attitudes towards teaching undergraduate medical students in the UK.

To achieve this aim, the review asked the following question:

What are the factors that influence consultants' attitudes towards and engagement in teaching undergraduate medical students in the UK?

\section{METHODS}

\section{Protocol}

The review protocol has been registered with the Open Science Framework (osf.io/fg24u).

\section{Search strategy and information sources}

Electronic searches of bibliographic databases (MEDLINE, EMBASE and OpenGrey) were carried out from inception to August 2019 using a search strategy with, where appropriate, index and free-text terms related to medical education, undergraduate students, consultants and attitudes. Terms were combined using the appropriate OR and AND operators (see MEDLINE search strategy in online supplemental appendix 1). Additionally, the websites of relevant journals with a focus on medical education were searched using terms from the search strategy.

\section{Eligibility criteria}

The following criteria were used to select studies for inclusion in this review.

Study design-studies using either qualitative methodology or some form of questionnaire/survey to elicit attitudes were included.

Study topic-only studies asking specifically about teaching of undergraduate medical students were included.

Participants—studies interviewing senior hospital doctors (defined as consultants or senior hospital practitioners) were included. These senior hospital doctors must been involved in teaching undergraduate medical students. While senior hospital doctors are also involved in training junior doctors (postgraduate medical education) and other healthcare personnel, this was not within the scope of this review, so any studies exclusively focusing on teaching of non-undergraduate medical students were not included. 
Country-only studies based in the UK were included. Studies from other countries were excluded as both their health service provision and undergraduate medical education may be of a different structure to that in the UK and therefore not relevant.

Setting - the participants of the studies must be based at a hospital or at a medical school with some part of their job involving delivering teaching within a hospital setting. General practitioners were excluded as their undergraduate teaching is not hospital based, and their pattern of employment (including time allocated to teaching) is typically quite different to that of hospital consultants.

Language—only studies in English were included.

\section{Study selection process}

Due to the number of records, $10 \%$ of titles and abstracts were initially screened by two reviewers independently using predefined eligibility criteria based on the design, topic and participants to identify potentially relevant articles. After discussion and consideration of reasons for any disagreements, the remaining titles and abstracts were screened by one reviewer.

The full texts of the potentially relevant articles were obtained and assessed against the full inclusion criteria by two reviewers independently. Endnote X7 software (Clarivate Analytics) was used to record study selection decisions, and reasons for exclusion were noted.

\section{Data extraction strategy}

Data extracted included author(s), publication year, setting of study, occupation of those surveyed/interviewed, number of responses, data collection method and main findings.

\section{Quality and risk of bias assessment}

Quality and risk of bias assessment of included articles was carried out by two reviewers independently using the CASP Qualitative Checklist. ${ }^{24}$ This tool assesses bias risk in several domains including participant recruitment and data analysis. Any discrepancies were resolved with a third reviewer.

\section{Methods of data analysis/synthesis}

Data synthesis and analysis was carried out using thematic analysis techniques following the thematic synthesis and meta synthesis processes described Thomas and Harden ${ }^{25}$ and outlined below. This process was carried out using NVivo software (QSR International).

Stage 1-line-by-line coding of the extracted data was carried out identifying the key findings from each study. Two of the included papers were coded by two reviewers independently and then codes were discussed to ensure similarity in understanding. The remaining three papers were then coded by one reviewer.

Stage 2-the codes were then analysed and subsequently grouped into related categories according to their similarities.

Stage 3-the categories were then compared with each other in order to identify similarities and differences between them. Similar categories were grouped into themes to synthesise the findings of the included studies.

\section{Patient and public involvement}

No patient involved.

\section{RESULTS}

A total of 4195 potentially relevant records were identified through the literature search. After removal of duplicate records and screening for relevance to the review, inclusion criteria were applied to 12 full-text articles. Five studies $^{24202627}$ were included in the review and seven excluded due to the following reasons: duplicate under different title (one article), ${ }^{28}$ incorrect country (one article), ${ }^{29}$ incorrect study topic (four articles) ${ }^{30-33}$ and unable to obtain full text (one article).$^{34}$ The authors of this final article were contacted to try to obtain the full text, however no response was received, so the article remained excluded. See figure 1.

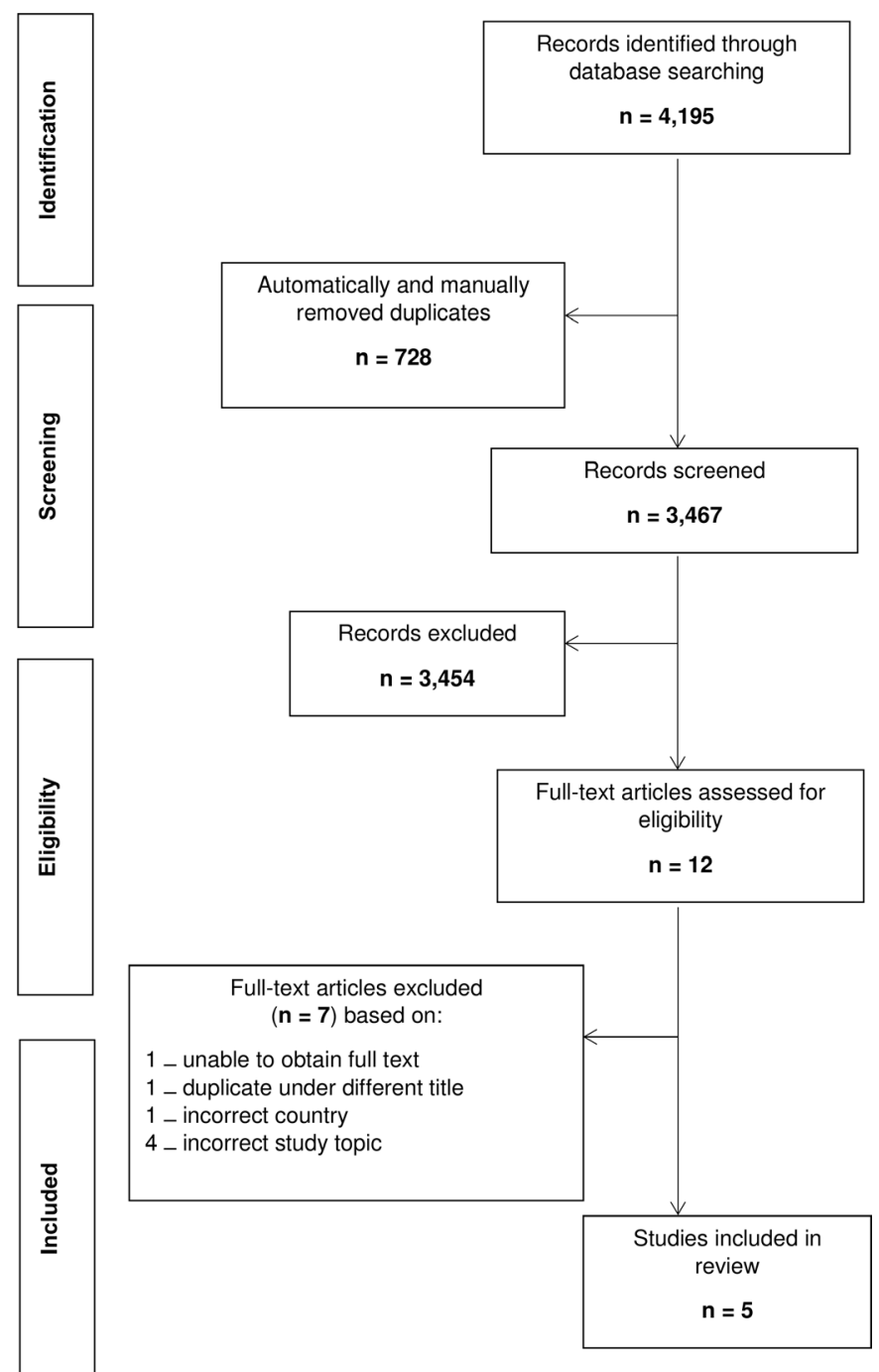

Figure 1 Preferred Reporting Items for Systematic Reviews and Meta-Analyses flow diagram detailing the search process for included studies. 


\begin{tabular}{|c|c|c|c|c|c|}
\hline Year & Study design & Participants & Response rate & Country & Setting \\
\hline 2015 & $\begin{array}{l}\text { Email questionnaire (Likert } \\
\text { scales and free-text } \\
\text { questions) }\end{array}$ & 367 consultants & $367 / 1372(27 \%)$ & $\begin{array}{l}\text { Northern } \\
\text { Ireland }\end{array}$ & $\begin{array}{l}\text { Hospitals in Northern } \\
\text { Ireland }\end{array}$ \\
\hline 2005 & $\begin{array}{l}\text { Postal questionnaire } \\
\text { (Likert scales and free-text } \\
\text { questions) }\end{array}$ & 308 consultants & $249 / 308(80.8 \%)$ & England & $\begin{array}{l}\text { Eight teaching } \\
\text { hospitals in West } \\
\text { Midlands }\end{array}$ \\
\hline 2006 & $\begin{array}{l}\text { In-depth semistructured } \\
\text { interviews }\end{array}$ & 13 clinicians & $13 / 45(28.8 \%)$ & England & $\begin{array}{l}\text { Three hospital trusts } \\
\text { associated with a new } \\
\text { medical school }\end{array}$ \\
\hline 2003 & Semistructured interviews & 13 consultants & Not reported & England & $\begin{array}{l}\text { Two teaching hospitals } \\
\text { in Leeds }\end{array}$ \\
\hline 2003 & $\begin{array}{l}\text { In-depth semistructured } \\
\text { interviews }\end{array}$ & $\begin{array}{l}22 \text { doctors ( } 15 \\
\text { senior) }\end{array}$ & $22 / 22(100 \%)$ & England & One medical school \\
\hline
\end{tabular}

The five included studies comprised one postal questionnaire, ${ }^{2}$ one email questionnaire ${ }^{4}$ and three semistructured interviews..$^{2627}$ The studies dated from 2003 to 2015 and included a total of 723 consultants working in England 202627 and Northern Ireland. ${ }^{4}$ Four studies were conducted in teaching hospitals ${ }^{2420} 27$ and one was conducted in a medical school. ${ }^{26}$ See table 1 for full study characteristics.

Mostly, the quality of the included papers was deemed to be good. Four of the papers had at least one domain where the required standard was not reached. Two papers did not give detailed information on how free-text comments from the questionnaires were coded or analysed, ${ }^{47}$ one paper did not provide sufficient details or justification regarding its recruitment strategy, ${ }^{20}$ and one paper was ambiguous in its description of consideration of ethical issues, ${ }^{20}$ but these domains were not felt to have a significant impact on the overall quality of the papers. Table 2 details the undertaken quality assessment.

Initially, 29 separate codes were created from the five included studies. These were then grouped into seven categories and finally two main themes were identified-Teaching Practicalities and Doctors versus Teachers.

\section{Teaching practicalities}

Consultants across all the included studies reported barriers to delivering undergraduate medical teaching that related to the practical issues surrounding a teaching session, including both planning and delivery. The most frequently reported barrier was lack of time, with consultants across all five studies identifying not having enough time for teaching as a factor. This included both time for delivering the teaching, and also adequately preparing for sessions. Some consultants reported any time allocated for teaching as being notional with the expectation that other duties were also fitted into this time, ${ }^{26}$ and some consultants described the steps taken to ensure that protected time for teaching remained protected such as delegating routine clinical work to junior staff. ${ }^{20}$
Further practical issues reported included a lack of suitable patients to be used for bedside teaching, ${ }^{26}$ lack of suitable space for delivering teaching in ${ }^{2026}$ and issues around large student group numbers. ${ }^{2} 4$ A response received to the survey conducted in Darragh's paper stated:

Small group teaching is impossible with groups of 28 students unless 3-4 senior doctors are available. ${ }^{4}$

Consultants reported being unable to plan topics for teaching as they were limited by the patients who were available on a day-to-day basis ${ }^{26}$ and others reported when a suitable patient could be found, there simply was not enough suitable space nearby to deliver the teaching in the style they wanted to. ${ }^{20}$ A doctor interviewed as part of Seabrook's paper was quoted as saying:

There's no good, quiet rooms on every ward where you could take a patient and have an uninterrupted-you tend to do it bedside, don't you? - and that, but it would be rather helpful if that was available [...] because quite often the wards are noisy, very noisy, and the day to day bustle of the ward is quite off putting for students when they're asked to listen to something or look at something. They find that quite difficult. ${ }^{26}$

\section{Doctors versus Teachers}

Within this theme, facilitators and barriers were identified from the dual, and sometimes conflicting, professional identities that consultants hold as both doctors and teachers. The studies reported facilitators such as consultants feeling it was their professional duty to provide teaching to students, and that teaching was an enjoyable part of the job. ${ }^{40}$ Barriers reported included feeling pressure to balance clinical performance with delivering teaching, and feeling separate from and having communication difficulties with the medical schools that their students came from. ${ }^{20}{ }^{26}$ Specific issues relating to the difficulties with medical schools included a lack of formal recognition for the teaching provided and feeling that their views/concerns about teaching students were not 
Table 2 Quality assessment of included studies

\begin{tabular}{|c|c|c|c|c|c|}
\hline & Darragh $^{4}$ & Hendry $^{2}$ & Knight $^{27}$ & Seabrook $^{26}$ & Stark $^{20}$ \\
\hline $\begin{array}{l}\text { Is a qualitative } \\
\text { methodology } \\
\text { appropriate? }\end{array}$ & Yes & Yes & Yes & Yes & Yes \\
\hline $\begin{array}{l}\text { Was the recruitment } \\
\text { strategy appropriate } \\
\text { to the aims of the } \\
\text { research? }\end{array}$ & Yes & Yes & Yes & Yes & No \\
\hline $\begin{array}{l}\text { Has the relationship } \\
\text { between researcher } \\
\text { and participants been } \\
\text { adequately considered? }\end{array}$ & Yes & No & Yes & Yes & Yes \\
\hline $\begin{array}{l}\text { Have ethical issues } \\
\text { been taken into } \\
\text { consideration? }\end{array}$ & Yes & Yes & Yes & Yes & No \\
\hline $\begin{array}{l}\text { Was the data analysis } \\
\text { sufficiently rigorous? }\end{array}$ & No & Yes & No & Yes & Yes \\
\hline
\end{tabular}

taken into consideration despite being responsible for part of their education. ${ }^{26}$ Another doctor interviewed as part of Seabrook's paper was quoted as saying:

You don't get any feedback from the medical school itself. You don't get any gratitude from the medical school. You don't get, you don't hear a word from them, you know and you know if you look at my contract there isn't-teaching's not mentioned, you know. ${ }^{26}$

Lack of recognition for their teacher identity was identified by several studies as a barrier, both in contractual and financial terms. ${ }^{2426}$ Consultants reported that they did not feel adequately financially rewarded for the time they dedicated to teaching, ${ }^{426}$ and that despite an expectation to teach, in two studies only a minority reported this was reflected in their contract. ${ }^{24}$

\section{DISCUSSION}

To the best of our knowledge, this is the first systematic review to synthesise qualitative evidence on consultant attitudes towards undergraduate medical education in the UK. With individual studies based in individual regions or hospitals, this review has been able to provide a more nationally applicable perspective on factors affecting consultants.
As only five studies were available for inclusion, this review was limited in its ability to generate new theoretical perspectives on this topic. However, across these five studies, the review has been able to draw together and identify common barriers and facilitators to consultants delivering teaching in several locations across the UK, resulting in two main themes.

Teaching practicalities mainly identifies the infrastructure-related barriers to delivering teaching such as lack of protected time and space for teaching. The existence of these issues is unsurprising as hospitals do not have the primary purpose of being education providing environments, but are seconded to this use through hosting medical students and the practical nature of clinical medical education. While for some issues, there is very little that could be changed, for example suitable patients available for teaching on planned topics, it would be possible to consider size of suitable teaching spaces when designing hospital buildings, and try to ensure that protected teaching time remains protected for that purpose.

The Doctors versus Teachers theme highlights the positive and negative aspects of having more than one professional identity, particularly relating to education. While it 
appears that consultants enjoy having an educator identity as well as a healthcare professional identity, conflicting priorities between the two can seemingly result in difficulties and feelings of resentment. With identifiable factors such as communication problems with medical schools and lack of recognition partly responsible for these conflicts, it would appear that there are areas that could be targeted by both hospitals and medical schools to address at least some of these barriers.

There were some limitations associated with the studies included in this review. For example, the studies did not all use the same design, with two of the studies using questionnaires, and three using interviews. Additionally, two of the studies had low response rates, meaning the findings may not be representative of the whole population invited to take part. Despite these limitations, the quality assessment carried out on the studies for this review shows that they were deemed to be providing good quality evidence and therefore any methodological limitations are not thought to have impacted on the findings of this review.

The scope of this review was to explore attitudes of consultants based in the UK, particularly following the significant increases in student numbers and changes in curricula that have occurred over the last 20 years. Studies based in countries outside the UK were therefore excluded at the title and abstract screening stage as undergraduate medical training in other countries does not always have the same structure as UK training and has not necessarily undergone the same changes as in the UK. Three studies were excluded for this reason, two based in Australia ${ }^{2935}$ and one based in Ireland, ${ }^{36}$ but we did consider these separately in order to get a perspective on the attitudes of senior doctors working in other countries. Similar facilitators (teaching being enjoyable) and barriers (lack of time, difficulties with institutions and difficulties balancing other duties with teaching) were identified across the three papers suggesting that some factors could be common worldwide.

It was somewhat surprising that only a small number of studies were available on this topic given the responsibility that consultants hold for educating undergraduate medical students across the UK. With the increase in medical student numbers and subsequent necessity for consultants to take on more teaching duties, as well as the major curriculum changes over the past 20 years, it would be expected that there would be a body of evidence available exploring this, but there is not. With only three additional identified studies based outside the UK (as mentioned above), this scarcity of evidence is seemingly not only limited to the UK, and there is no obvious explanation for the lack of interest in this area.

The included studies span 12 years demonstrating that the facilitators and barriers identified are persistent over time. With the planned increases in medical student numbers, the themes identified in this review will continue to be relevant to those delivering undergraduate teaching, particularly those relating to Teaching Practicalities. However, with the exception of the study by Darragh et al, the included studies were from 2006 and earlier, meaning that there could well be some limitations in the applicability of the evidence to current consultant teaching practice. While some of the factors affecting consultant led teaching will have remained the same in the time since then, more recent developments in medical education, such as the creation of the specific teaching jobs for junior doctors (CTF posts), will have been missed by these early studies and therefore not included in this review. In terms of the impact, these developments in medical education may have had, it could be, for example, that the CTF posts have been created as a response to some of the issues facing consultants regarding the delivery of teaching. It is also possible that the barriers identified in the Teaching Practicalities theme, particularly lack of time, could be a driving factor in the expansion of the number of CTF posts. However, in the absence of research on this topic, this must remain as speculation. Having identified barriers relevant to consultant led teaching in this review, and knowing that more recent junior teaching posts exist, an area for future research to explore would be whether there is any link between the two. Additionally, it would be of interest to know if similar issues identified in this review are faced by junior teaching staff, and to explore whether the introduction of such posts has removed or eased any of the barriers reported by consultants.

\section{CONCLUSION}

This review has identified several factors impacting on consultant led undergraduate medical teaching in the UK and has been able to draw together evidence previously restricted to individual geographical regions. While only a small number of mostly older studies (10+ years) were available, the factors identified by the review are likely to still be relevant as they are mostly based on infrastructure and professional identity. Further research on recent developments in medical education would give a more complete picture of the facilitators and barriers to delivering undergraduate medical education.

\section{Twitter Derek J Ward @DWard_Bham}

Contributors IMH and JP designed the study. All authors oversaw its implementation. IMH coordinated and did all review activities, including searches, study selection, data extraction and quality assessment. HB carried out study selection as second reviewer. HMN carried out data extraction and quality assessment as second reviewer. IMH and JP planned the analyses and IMH conducted these. IMH wrote the initial draft and HMN, HB, AJS, DJW and JP contributed writing to subsequent versions of the manuscript. All authors reviewed the study findings and read and approved the final version before submission.

Funding The authors have not declared a specific grant for this research from any funding agency in the public, commercial or not-for-profit sectors.

Competing interests None declared.

Patient consent for publication Not required.

Provenance and peer review Not commissioned; externally peer reviewed.

Data availability statement Data sharing not applicable as no data sets generated and/or analysed for this study. No additional data available. 
Supplemental material This content has been supplied by the author(s). It has not been vetted by BMJ Publishing Group Limited (BMJ) and may not have been peer-reviewed. Any opinions or recommendations discussed are solely those of the author(s) and are not endorsed by BMJ. BMJ disclaims all liability and responsibility arising from any reliance placed on the content. Where the content includes any translated material, BMJ does not warrant the accuracy and reliability of the translations (including but not limited to local regulations, clinical guidelines, terminology, drug names and drug dosages), and is not responsible for any error and/or omissions arising from translation and adaptation or otherwise.

Open access This is an open access article distributed in accordance with the Creative Commons Attribution Non Commercial (CC BY-NC 4.0) license, which permits others to distribute, remix, adapt, build upon this work non-commercially, and license their derivative works on different terms, provided the original work is properly cited, appropriate credit is given, any changes made indicated, and the use is non-commercial. See: http://creativecommons.org/licenses/by-nc/4.0/.

\section{ORCID iDs}

Isobel Marion Harris http://orcid.org/0000-0001-8125-3832

Derek J Ward http://orcid.org/0000-0003-0740-9741

\section{REFERENCES}

1 Department of Health. The NHS plan. A plan for investment. A plan for reform. London: Stationery Office, 2000.

2 Hendry RG, Kawai GK, Moody WE, et al. Consultant attitudes to undertaking undergraduate teaching duties: perspectives from hospitals serving a large medical school. Med Educ 2005;39:1129-39.

3 Lewington $\mathrm{K}$. Changes to medical education over the past 20 years. BMJ 2012;344.

4 Darragh L, Baker R, Kirk S. Teaching medical students, what do consultants think? Ulster Med J 2015;84:37-41.

5 General Medical Council. Tomorrow's Doctors: Recommendations on Undergradaute Medical Education. London: General Medical Council, 2002.

6 Royal College of Physicians. Double or quits: calculating how many more medical students we need 2018.

7 Department of Health. Expansion of undergraduate medical education government response to consultation. London, 2017.

8 General Medical Council. The state of medical education and practice in the UK. London 2018.

9 Blake T. Teaching musculoskeletal examination skills to UK medical students: a comparative survey of rheumatology and orthopaedic education practice. BMC Med Educ 2014;14:62.

10 Coady D, Walker D, Kay L. The attitudes and beliefs of clinicians involved in teaching undergraduate musculoskeletal clinical examination skills. Med Teach 2003;25:617-20.

11 Khan MM, Saeed SR. Provision of undergraduate otorhinolaryngology teaching within general medical Council Approved UK medical schools: what is current practice? J Laryngol Otol 2012;126:340-4.

12 Marino K, Merrick D, Edwards K, et al. Musculoskeletal radiology teaching at a UK medical school: do we need to improve? Anat Sci Educ 2019;12:257-63.

13 Mulholland D, McEntee G, Quinlan C, et al. Unscheduled undergraduate teaching in surgery: a multi-institutional analysis. Ir Med J 2014;107:85-7.
14 Waterston SW, Stewart IJ. Survey of clinicians' attitudes to the anatomical teaching and knowledge of medical students. Clin Anat 2005;18:380-4

15 Barber JRG, Park SE, Jensen K, et al. Facilitators and barriers to teaching undergraduate medical students in general practice. Med Educ 2019;53:778-87.

16 Rushforth B, Kirby J, Pearson D. General practice registrars as teachers: a review of the literature. Educ Prim Care 2010;21:221-9.

17 Harding A, Sweeney G. How does an increase in undergraduate teaching load affect GP teacher motivation? A grounded theory study using data from a new medical school. Educ Prim Care 2013;24:237-43.

18 Sturman N, Régo P, Dick M-L. Rewards, costs and challenges: the general practitioner's experience of teaching medical students. Med Educ 2011;45:722-30.

19 Thomson J, Haesler E, Anderson K, et al. What motivates general practitioners to teach. Clin Teach 2014;11:124-30.

20 Stark P. Teaching and learning in the clinical setting: a qualitative study of the perceptions of students and teachers. Med Educ 2003;37:975-82.

21 Woodfield G, O'Sullivan M. Clinical teaching fellows: everyone's a winner. Clin Teach 2014;11:136-40.

22 Wilson S, Denison AR, McKenzie H. A survey of clinical teaching fellowships in UK medical schools. Med Educ 2008;42:170-5.

23 Ker R, Guckian J, Bowey AJ. 'Just a year out'? - Challenges of the clinical teaching fellow. MedEdPublish 2018;7.

24 Critical Appraisal Skills Programme. Casp qualitative checklist. [Online] 2019 https://Casp-Uk.Net/Wp-Content/Uploads/2018/01/ Casp-Qualitative-Checklist-2018.Pdf Accessed: 14/03/2019

25 Thomas J, Harden A. Methods for the thematic synthesis of qualitative research in systematic reviews. BMC Med Res Methodol 2008;8:45.

26 Seabrook MA. Medical teachers' concerns about the clinical teaching context. Med Educ 2003;37:213-22.

27 Knight LV, Bligh J. Physicians' perceptions of clinical teaching: a qualitative analysis in the context of change. Adv Health Sci Educ Theory Pract 2006;11:221-34.

28 Darragh L. Attitudes of consultants to teaching medical students in small group settings. Ulster Medical Journal 2016;85:216.

29 Hartford W, Nimmon L, Stenfors T. Frontline learning of medical teaching: "you pick up as you go through work and practice". BMC Med Educ 2017;17:171.

30 Gibson DR, Campbell RM. Promoting effective teaching and learning: Hospital consultants identify their needs. Med Educ 2000;34:126-30.

31 McKinstry B, Macnicol M, Elliot K, et al. The transition from learner to provider/teacher: the learning needs of new orthopaedic consultants. BMC Med Educ 2005;5:17.

32 Wall D, McAleer S. Teaching the consultant teachers: identifying the core content. Med Educ 2000;34:131-8.

33 Cowan FM, Adler MW. Survey of undergraduate teaching in genitourinary medicine in Britain. Genitourin Med 1994;70:311-3.

34 Schofield SJ, Nathwani D, Anderson F. Scottish associate specialists: their educational qualifications, teaching experience and training needs compared to Scottish consultants. Medical Education, Supplement 2010;44:108

35 Dahlstrom J, Dorai-Raj A, McGill D, et al. What motivates senior clinicians to teach medical students? BMC Med Educ 2005;5:27.

36 Walsh K, Ahern S, Condon E, et al. Anaesthetic specialist registrars in Ireland: current teaching practices and perceptions of their role as undergraduate teachers. Eur J Anaesthesiol 2004;21:824-8. 